\title{
Impact of breath-hold level on positional error aligned by stent/Lipiodol in Hepatobiliary radiotherapy with breath- hold respiratory control
}

Tzu-Jie Huang ${ }^{1,2}$, Yun Tien ${ }^{3,4}$, Jian-Kuen Wu', Wen-Tao Huang ${ }^{2^{*}}$ and Jason Chia-Hsien Cheng ${ }^{1,5,6^{*}}$ (D)

\begin{abstract}
Background: Respiratory motion management with breath hold for patients with hepatobiliary cancers remain a challenge in the precise positioning for radiotherapy. We compared different image-guided alignment markers for estimating positional errors, and investigated the factors associated with positional errors under breath-hold control.

Methods: Spirometric motion management system (SDX) for breath holds was used in 44 patients with hepatobiliary tumor. Among them, 28 patients had a stent or embolized materials (lipiodol) as alignment markers. Cone-beam computed tomography $(\mathrm{CBCT})$ and kV-orthogonal images were compared for accuracy between different alignment references. Breath-hold level $(B H L)$ was practiced, and $B H L$ variation $(\triangle B H L)$ was defined as the standard deviation in differences between actual BHLs and baseline BHL. Mean BHL, $\triangle B H L$, and body-related factors were analyzed for the association with positional errors.

Results: Using the reference CBCT, the correlations of positional errors were significantly higher in those with stent/ lipiodol than when the vertebral bone was used for alignment in three dimensions. Patients with mean BHL $>1.4 \mathrm{~L}$ were significantly taller ( $167.6 \mathrm{~cm}$ vs. $161.6 \mathrm{~cm}, p=0.03)$ and heavier $(67.1 \mathrm{~kg}$ vs. $57.4 \mathrm{~kg}, p=0.02)$, and had different positional error in the craniocaudal direction $(-0.26 \mathrm{~cm}$ [caudally] vs. $+0.09 \mathrm{~cm}$ [cranially], $p=0.01)$ than those with mean $\mathrm{BHL}<1.4 \mathrm{~L}$. Positional errors were similar for patients with $\triangle \mathrm{BHL}<0.03 \mathrm{~L}$ and $>0.03 \mathrm{~L}$.

Conclusion: Under rigorous breath-hold respiratory control, BHL correlated with body weight and height. With more accurate alignment reference by stent/lipiodol, actual BHL but not breath-hold variation was associated with craniocaudal positional errors.
\end{abstract}

Keywords: Radiotherapy, Breath holding, Hepatocellular carcinoma, Patient positioning, Radiotherapy planning, Computer-assisted/methods

\footnotetext{
*Correspondence: huangwt@mail.ypu.edu.tw; jasoncheng@ntu.edu.tw

2Department of Medical Imaging and Radiological Technology, Yuanpei

University of Medical Technology, 306 Yuanpei Street, Hsinchu 30015, Taiwan

'Division of Radiation Oncology, Department of Oncology, National Taiwan

University Hospital, National Taiwan University College of Medicine, No. 7,

Chung-Shan South Rd, Taipei 10002, Taiwan

Full list of author information is available at the end of the article
}

(c) The Author(s). 2020 Open Access This article is licensed under a Creative Commons Attribution 4.0 International License, which permits use, sharing, adaptation, distribution and reproduction in any medium or format, as long as you give appropriate credit to the original author(s) and the source, provide a link to the Creative Commons licence, and indicate if changes were made. The images or other third party material in this article are included in the article's Creative Commons licence, unless indicated otherwise in a credit line to the material. If material is not included in the article's Creative Commons licence and your intended use is not permitted by statutory regulation or exceeds the permitted use, you will need to obtain permission directly from the copyright holder. To view a copy of this licence, visit http://creativecommons.org/licenses/by/4.0/ The Creative Commons Public Domain Dedication waiver (http://creativecommons.org/publicdomain/zero/1.0/) applies to the data made available in this article, unless otherwise stated in a credit line to the data. 


\section{Introduction}

Hepatocellular carcinoma is a common gastrointestinal cancer with no obvious symptoms at early stage or diagnosis. In recent years, radiotherapy has become a noninvasive treatment option. Many studies indicate that radiotherapy improves the local control rate and median survival of patients with liver cancer [1-3]. With the recent development of linear accelerators and radiotherapy technology such as multi-leaf collimators, flattening filter-free mode, image-guided radiotherapy (IGRT), and stereotactic body radiotherapy (SBRT), higher doses can be delivered to tumors for better biological effect because the treatment plan can be more complex and the dose gradient can be steeper $[4,5]$. However, the liver is located near the diaphragm, creating a challenge to measure the tumor motion and deformation caused by respiratory movement. According to the American Association of Physicists in Medicine (AAPM) Task Group Report no. 76, motion management strategies should be used during radiotherapy in patients whose breathing motion exceeds $5 \mathrm{~mm}$ [6]. Deep inspiration breath-hold $(\mathrm{DIBH})$ is one method which reduces the margin of planning target volume (PTV) and provides for accurate dose delivery [7]. Combining DIBH with IGRT in radiotherapy can enhance positioning reproducibility and facilitate dose escalation [8-11].

One spirometric motion management system, the socalled SpiroDynr'X system $\left(\mathrm{SDX}^{\mathrm{TM}}\right.$ system), is a computer-controlled device that assists in voluntary breath hold. The system includes a very sensitive spirometer to quantify inspiration volume and establishes patient feedback by using video goggles, similar to virtual reality goggles. The patient can inhale to reach the defined target zone, then hold the breath while using visual data for reinforcement [12]. The preset breathhold range of the $\mathrm{SDX}^{\mathrm{sm}}$ system can improve the reproducibility of the predetermined phase of the breathing cycle [13]. Thus, the use of the $\mathrm{SDX}^{\mathrm{m}}$ system has been one of the breath-hold systems integrated into radiotherapy treatment for hepatobiliary cancer.

Of note, the changes in the inter-fraction liver position relative to vertebral bodies were significantly larger than in the intra-fraction liver position reported in previous studies [14]. A two-dimensional, offline imaging technique has been used to measure the motion of the liver tumor with other radiopaque markers used to correct the systematic error [15]. However, the random error generated in PTV with two-dimensional offline images guided by vertebral bodies led to geometry uncertainty and increased the radiation dose in the surrounding critical normal tissue [16].

The purpose of this study is to investigate the association of the breath-hold level (BHL), the variation in BHL, and the body-related factors with the positional errors in patients undergoing radiotherapy under a rigorous breath-hold control with SDX.

\section{Methods \\ Patients}

We reviewed 59 patients (48 males and 11 females) who had primary or metastatic hepatobiliary cancer (liver, bile duct, and gallbladder) and underwent radiotherapy using the SDX system with normal lung function from May, 2014 to March, 2018. Among these 59 patients, we initially excluded 17 patients with only the data either from CBCT alignment or from vertebral alignment. The remaining 42 patients were eligible for the following two analyses. Twenty-three patients were analyzed to compare the correlation between CBCT and two alignment methods (vertebra and stent) on orthogonal images. Twenty-eight patients with either stent or embolized materials (lipiodol) were eligible for the analysis of body related factors. Flow chart of the recruited patients is shown in Fig. 1. Patient characteristics are listed in Table 1.

\section{SDX system}

The SDX system (SpiroDynr'X system ${ }^{\bullet}$, Muret, France) was used in simulation and radiotherapy for patients with computer-controlled voluntary breath hold. The system includes the SDX module, video goggles, utility module, calibration syringe, laptop, and SDX software. The SDX module is comprised of a sensor connected to a mouthpiece and spirometer. Patient feedback can be set by using nose clips to force breathing from the mouth, and video goggles allow the patient to watch their own spirometry pattern to improve breath holding.

\section{Simulation and preparation}

All patients were immobilized with vacuum cushions, and underwent computed tomography (CT) simulation using a Philips Brilliance Big Bore CT (Philips, Eindhoven, Netherlands) for treatment planning. When the CT images were acquired, patients were asked to inhale to reach the predefined range and then hold the breath. The target volume and organs at risk were contoured and planned using the Eclipse ${ }^{\mathrm{Tx}}$ (V13.0, Varian Medical Systems Inc., Palo Alto, CA, USA) treatment planning system.

The BHLs of deep inspiration were practiced and determined in simulation. When patients used the SDX system for the first time, they breathed freely through the spirometer until being instructed to take a full inspiration in order to determine the inspiratory capacity; they did these three times to assure the reproducibility of breathing patterns. The BHL was defined as $85 \%$ of the maximum inspiratory capacity to ensure the patient's tolerance to complete multiple breathing cycles during fractionated radiotherapy $[17,18]$. Inspiration zone 


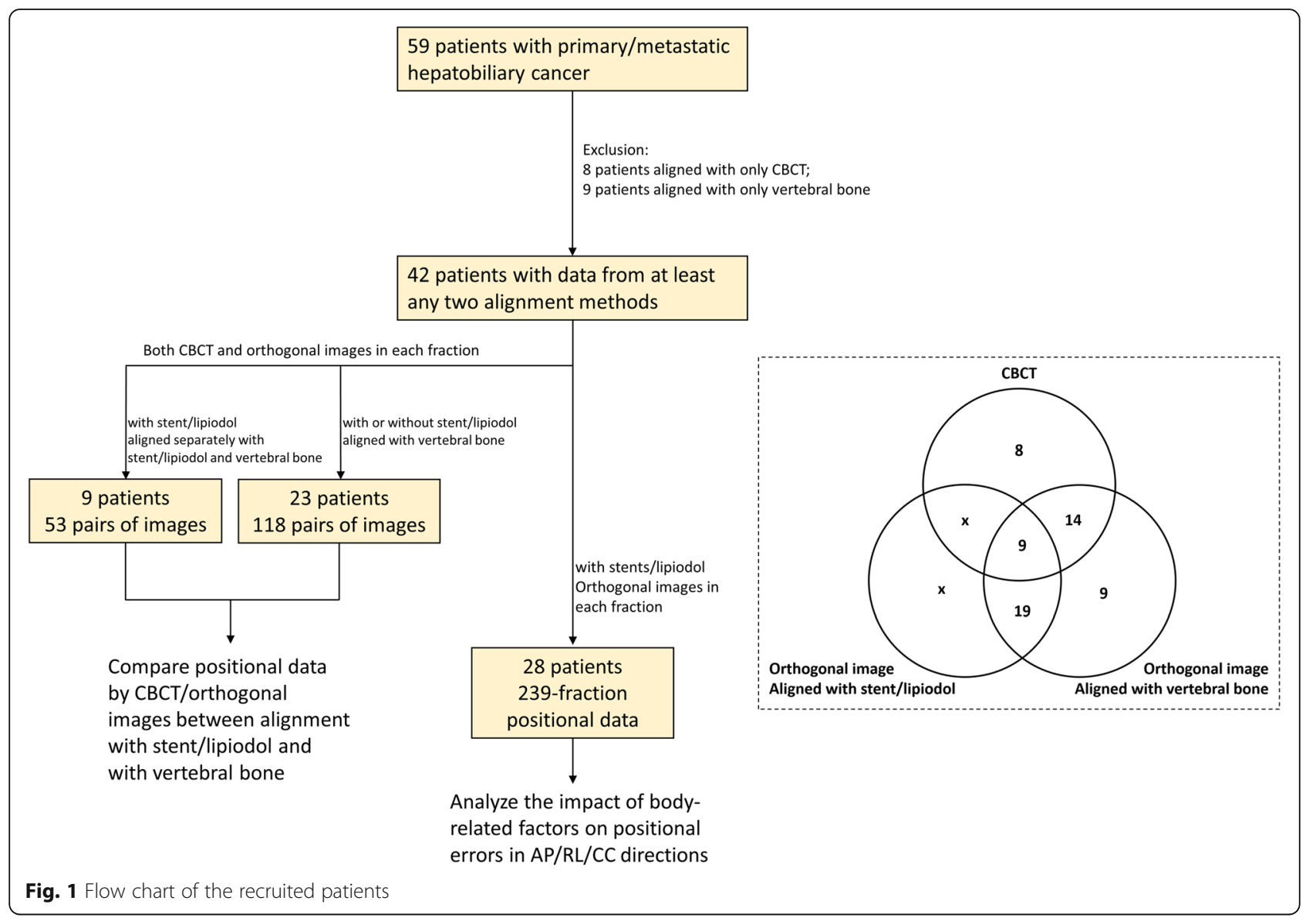

(breath-hold range) was defined as the $\mathrm{BHL} \pm 0.1 \mathrm{~L}$ (Supplementary Fig. 1A).

\section{Radiotherapy with image guidance}

The linear accelerator used for radiotherapy was the TrueBeam system (Varian Medical System Inc., Palo Alto, CA, USA), with $6 \mathrm{MV}$ or $10 \mathrm{MV}$ photons. The $\mathrm{kV}$ orthogonal images $(75 \mathrm{kV}, 200 \mathrm{~mA}, 25 \mathrm{~ms}$ and $95 \mathrm{kV}$, $200 \mathrm{~mA}, 200 \mathrm{~ms})$ or cone-beam (CB) CT $(125 \mathrm{kV}$ and $264 \mathrm{mAs}$ ) were taken before each treatment using Varian's On-Board Imager (OBI) system to confirm the accuracy of position, and the treatment couch was immediately adjusted to correct for the positional errors (Fig. 2). With the longer time required to take CBCT, some patients were not able to hold their breaths for acquiring $\mathrm{CBCT}$. In comparison, $\mathrm{kV}$-orthogonal images, which took shorter acquisition time, were technically applicable and more frequently used in our patients. Generally, the $\mathrm{kV}$-orthogonal images were more frequently obtained than CBCT for the best acquisition in a single breath hold. CBCT was needed when the alignment of the treated targets required the structural information inside the liver, especially in patient with no placement of fiducial markers. For the treatment session, the breath-hold range was displayed on the SDX module and patients started taking a breath to reach the BHL (Supplementary Fig. 1B). Patients needed to maintain breath-holds for at least $25 \mathrm{~s}$ with the same inspiratory volume every time, for radiation dose delivery and image acquisition.

\section{Analysis of the accuracy of different image-guided alignment markers}

In each fraction of treatment, acquired CBCT or orthogonal $\mathrm{kV}$ images were compared with the planning images for the alignment and the inter-fractional positional errors by a qualified radiation oncologist. The interfractional positional errors were recorded in the anterior-posterior (AP), cranial-caudal (CC), and rightleft (RL) directions. The shifts derived from CBCT alignment were used as baseline, and Pearson's correlation coefficient was calculated to compare the accuracy of using different alignment markers on $\mathrm{kV}$-orthogonal images (Fig. 3).

\section{Statistical analysis}

This is a retrospective analysis of a patient cohort for DIBH in hepatobiliary radiotherapy. Each breath-hold 
Table 1 Patient characteristics

\begin{tabular}{lll}
\hline Characteristics & Number & Percent \\
\hline Gender & 22 & 78.6 \\
Male & 6 & 21.4 \\
Female & & \\
Age & 63.5 & \\
Median & $38-78$ & \\
Range & & \\
Height (cm) & 166 & \\
Median & $147-176$ & \\
Range & & \\
Weight (kg) & 64.9 & \\
Median & $40.2-81.7$ & 10.7 \\
Range & & \\
BMl & 22.81 & 14.3 \\
Median & $16.40-30.07$ & \\
Range & & \\
Disease & 15 & \\
HCC & 4 & \\
Liver metastasis & 3 & \\
Pancreas cancer & 4 & \\
Cholangiocarcinoma & & \\
Gallbladder cancer & & \\
\hline
\end{tabular}
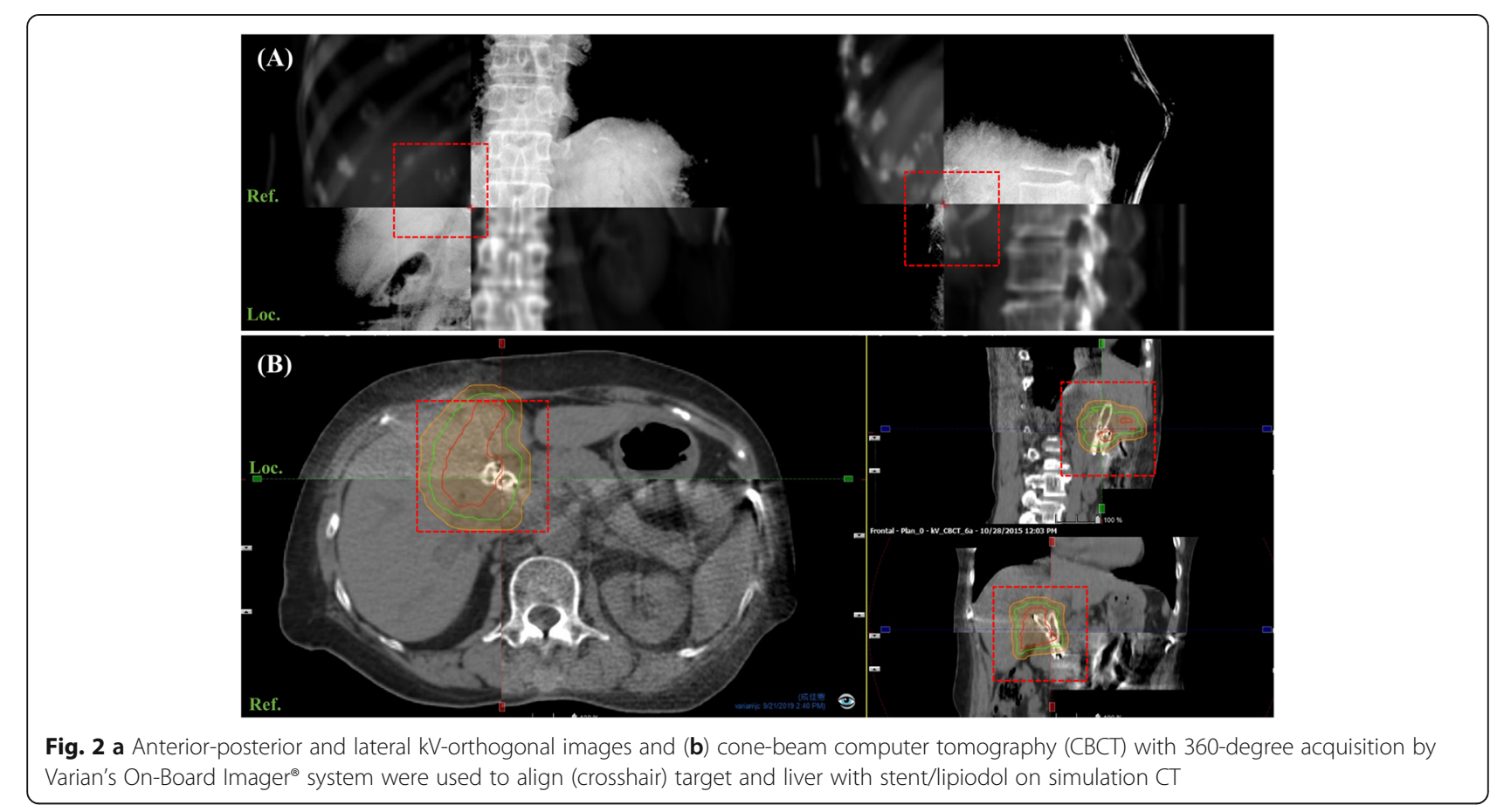

Fig. 2 a Anterior-posterior and lateral kV-orthogonal images and (b) cone-beam computer tomography (CBCT) with 360-degree acquisition by Varian's On-Board Imager ${ }^{\otimes}$ system were used to align (crosshair) target and liver with stent/lipiodol on simulation CT value of patients during their treatment was collected. The BHL variation $(\triangle \mathrm{BHL})$ was defined as the standard deviation in difference between each breath-hold value and the baseline BHL. Mean BHL was defined as the average of each patient's BHL during treatment. A total of $239 \mathrm{kV}$-orthogonal images by OBI system were analyzed for positional errors based on the stent/lipiodol position close to the tumor in the AP, CC, and RL directions. Patients were divided into two groups by the cutoff value close to mean BHL or $\triangle \mathrm{BHL}$ to compare the position shifts. Body weight and height of patients were measured on the simulation day. IBM SPSS Statistics version 22.0 software (IBM Corp., Armonk, NY) was used for Pearson correlation analysis. Data were presented as the mean \pm standard deviation for the indicated metrics. Differences between pairs of physique group were tested using the Student's t-test, and a $p$ value less than 0.05 was considered statistically significant.

\section{Results}

Among 42 patients included in this study, 118 pairs of images from 23 patients (without stent/alignment) with both $\mathrm{CBCT}$ and $\mathrm{kV}$-orthogonal images positioned with vertebral bones and 53 pairs of images from 9 patients (with stent/alignment) with CBCT and $\mathrm{kV}$-orthogonal images aligned separately with vertebral bodies and with stent/lipiodol were analyzed. Pearson's correlation coefficient was calculated to compare the accuracy of the two alignment methods on $\mathrm{kV}$-orthogonal images. As shown in Fig. 4, correlation was significantly better with stent/ 


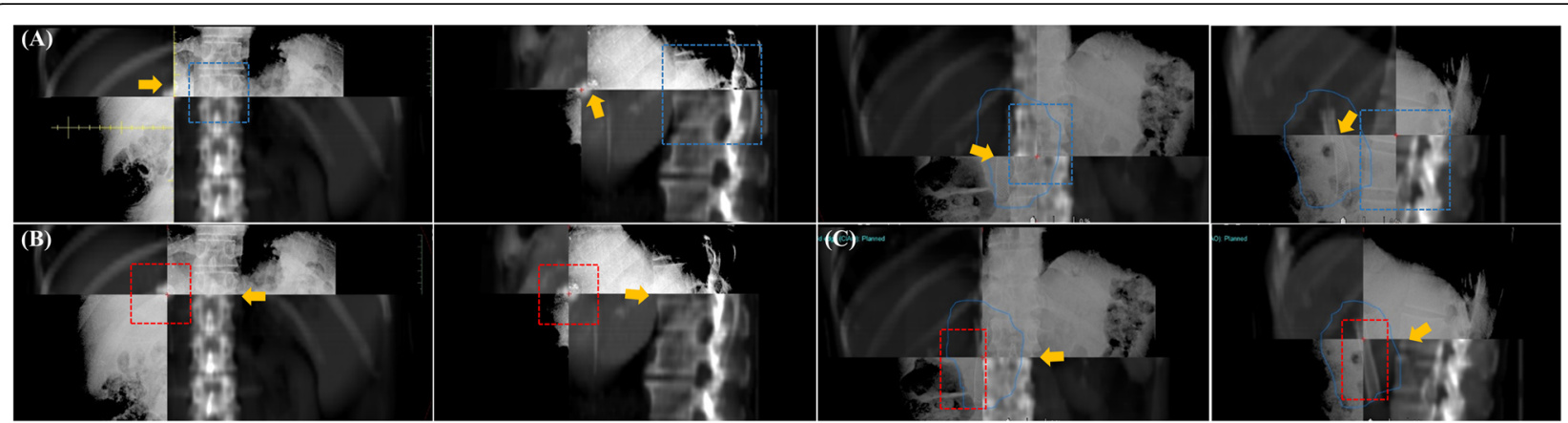

Fig. 3 Alignment strategies with different markers on paired kV-orthogonal images with crosshair were based on (a) vertebral bony structure (upper panels), (b) lipiodol, and (c) stent (lower panels)

lipiodol than with vertebral bone in the AP $(r=0.996$, $p<0.001$ vs. $r=0.529, p<0.001)$, CC $(r=0.996$, $p<0.001$ vs. $r=0.543, p<0.001)$, and RL axis $(r=0.982$, $p<0.001$ vs. $r=0.507, p<0.001)$.

The 28 patients using the SDX system maintained a median breath-hold interval of $30 \mathrm{~s}$ (range: $25-40 \mathrm{~s}$ ). The average BHL was $1.41 \mathrm{~L}$ (range: 0.76-2.08 L). $\triangle \mathrm{BHL}$ ranged from $0.011 \mathrm{~L}$ to $0.041 \mathrm{~L}$, with a median $\triangle \mathrm{BHL}$ of $0.031 \mathrm{~L}$. The positional errors in the AP, CC, and RL directions were $-0.05 \pm 0.25 \mathrm{~cm}, \quad-0.09 \pm 0.37 \mathrm{~cm}$ and $0.04 \pm 0.24 \mathrm{~cm}$, respectively.

Patients with mean BHL $>1.4 \mathrm{~L}$ were significantly taller $(167.6 \mathrm{~cm}$ vs. $161.6 \mathrm{~cm}, p=0.03)$ and heavier $(67.1 \mathrm{~kg}$ vs. $57.4 \mathrm{~kg}, p=0.02)$ than those with $\mathrm{BHL}<1.4 \mathrm{~L}$ (Fig. 5a). In addition, significantly larger positional errors in the CC direction $(-0.26 \mathrm{~cm}$ [caudally] vs. $+0.09 \mathrm{~cm}$ [cranially], $p=0.01)$, but similar shifts in the AP $(-0.13$ $\mathrm{cm}$ vs. $+0.04 \mathrm{~cm}, p=0.08)$ and RL direction $(+0.00 \mathrm{~cm}$ vs. $+0.08 \mathrm{~cm}, p=0.35$ ), were found in patients with mean $\mathrm{BHL}>1.4 \mathrm{~L}$ compared to those with $\mathrm{BHL}<1.4 \mathrm{~L}$, respectively (Fig. 5b). The correlations were not statistically significant between BHL and positional errors in $\mathrm{AP}(r=0.269, p=0.18), \mathrm{CC}(r=0.041, p=0.84)$, and RL $(r=0.024, p=0.91)$ directions, respectively. Other patient-related factors, including age, liver volume, and gross tumor volume, were not significantly associated with positional error (Table 2).

Under the rigorous protocol for breath-hold precision, the positional errors did not significantly differ between patients with $\triangle \mathrm{BHL}<0.03 \mathrm{~L}$ and $\triangle \mathrm{BHL}>0.03 \mathrm{~L}$ in the AP $(-0.015 \mathrm{~cm}$ vs. $-0.106 \mathrm{~cm}, p=0.31), \mathrm{CC}(-0.081 \mathrm{~cm}$ vs. $-0.090 \mathrm{~cm}, p=0.95)$, and RL $(0.066 \mathrm{~cm}$ vs. $-0.006 \mathrm{~cm}$, $p=0.45$ ) directions (Table 2).

Height and weight correlated with mean BHL $(r=0.605$ and $0.502, p=0.001$ and 0.007 , respectively). The Pearson correlation coefficient between mean BHL and positional error in the CC direction was -0.346 $(p=0.071)$. BHL was not correlated with positional errors in the AP $(r=0.270, p=0.165)$ or RL $(r=0.244, p=$ $0.211)$ direction. There was no correlation between

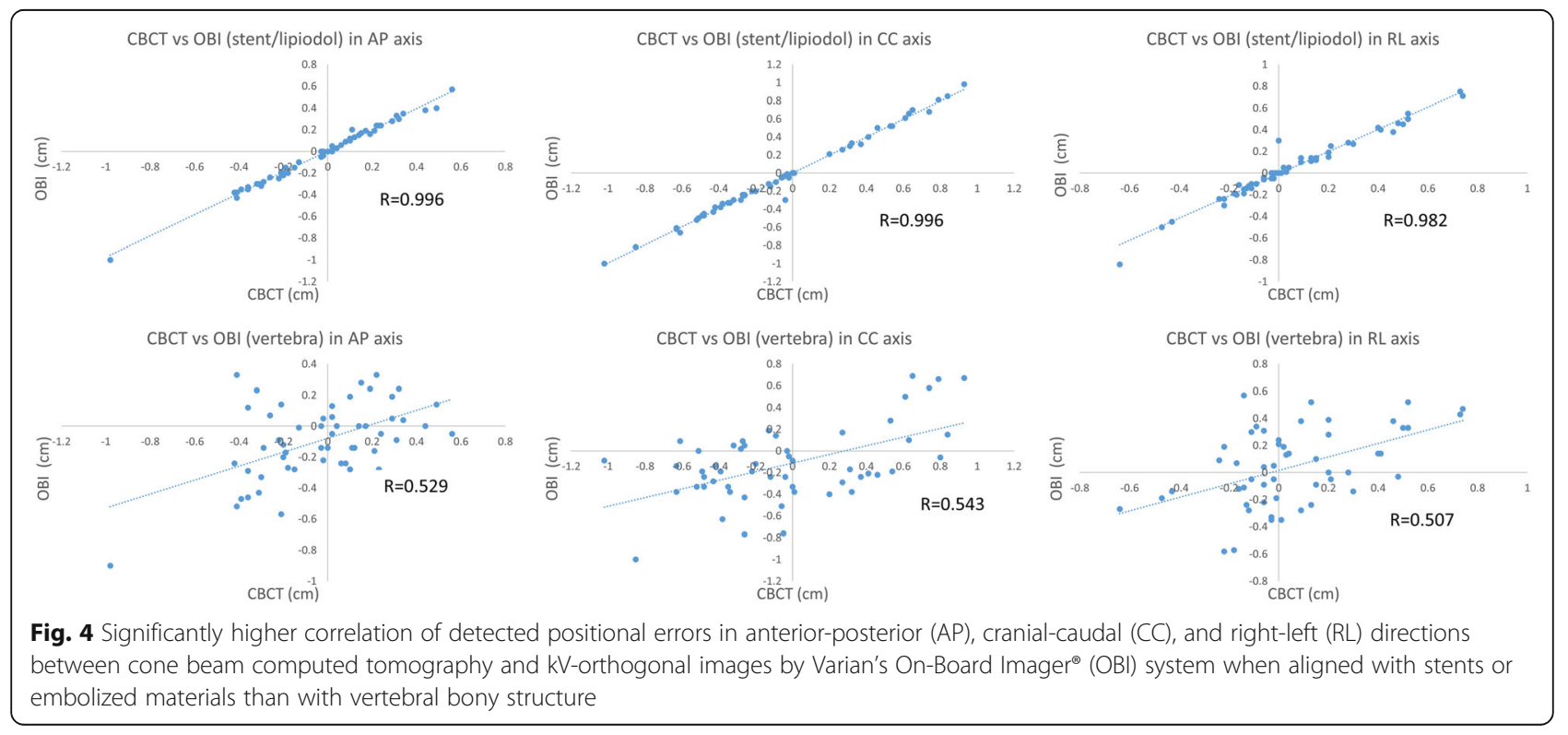




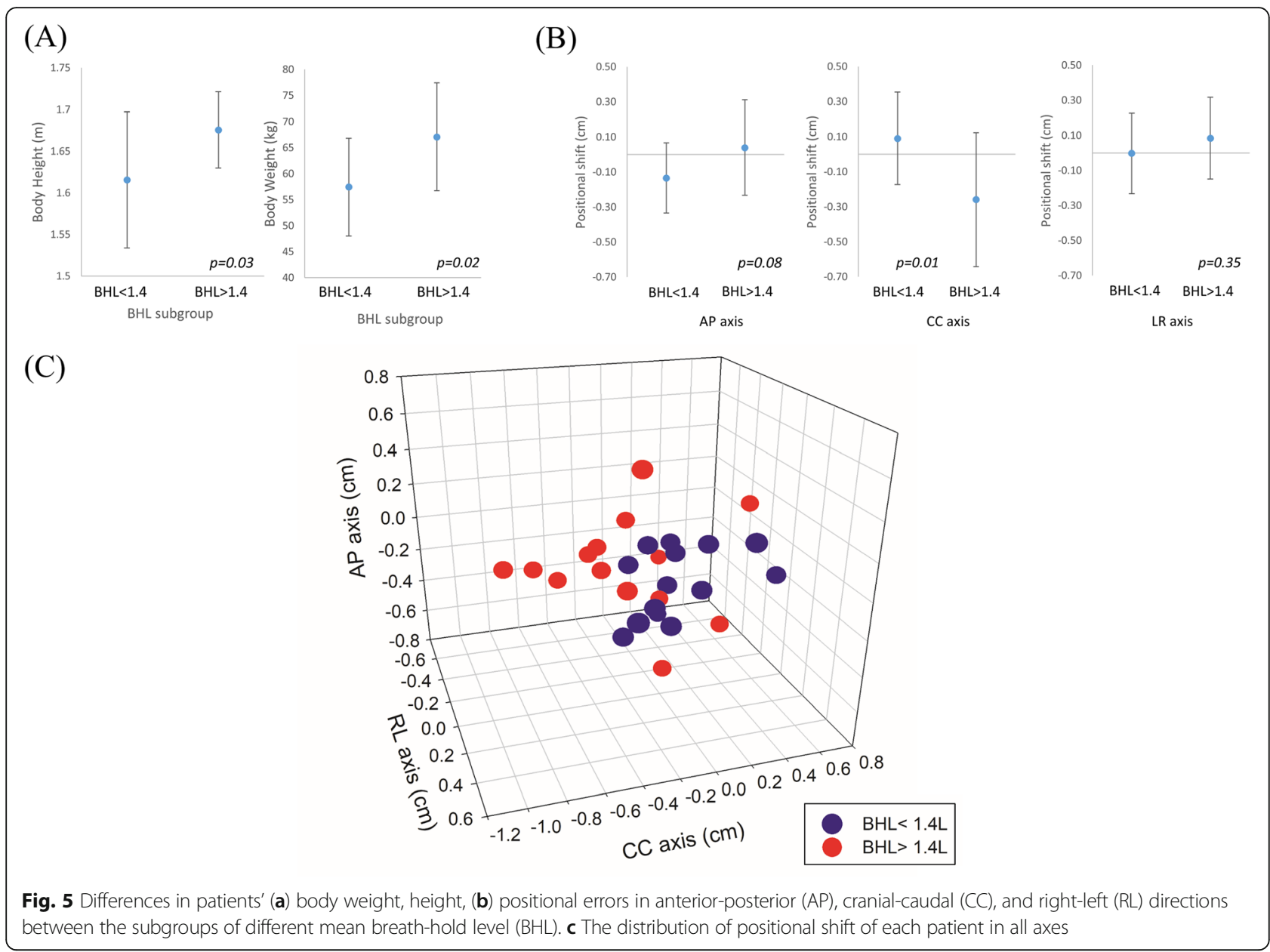

$\triangle \mathrm{BHL}$ and positional errors in the AP $(r=-0.147, p=$ $0.456)$, CC $(r=0.031, p=0.874)$, or RL $(r=0.024, p=$ $0.902)$ directions.

\section{Discussion}

Treating liver cancer with radiotherapy remains a challenge because of the surrounding critical organs. Although vertebral bodies have been used as alignment positions for liver radiotherapy, especially in the AP and $\mathrm{RL}$ directions, one study found that the errors in CC direction and the irregular three-dimensional liver motion could not be detected by orthogonal images [17]. On the other hand, $\mathrm{kV}-\mathrm{CBCT}$, with its volumetric information, provides improved accuracy of radiotherapy through visualization of the liver and the surrounding soft tissue. Using CBCT inevitably costs more than using twodimensional images $[16,19,20]$. Therefore, to align the liver using an implanted radiopaque marker close to the target lesion under orthogonal image guidance is now a common and acceptable method [21]. Our study consistently demonstrated that the correlation of the target positions under CBCT image guidance was significantly higher in all three dimensions on orthogonal images aligned with the stent/lipiodol than in those with vertebral body alignment.

Normal liver tissue is sensitive to radiation, and breathing inevitably affects the liver position through diaphragm movement. Therefore, respiratory control is needed to reduce treatment uncertainty and achieve accurate dose coverage. With breath hold using an active breathing coordinator (ABC) (Elekta Oncology Systems, Crawley, UK), the intra-fractional positional error and reproducibility in hepatobiliary radiotherapy were all less than those reported previously $[9,10,22]$. The mean intra- and inter-fraction positional errors in the CC direction were $1.9 \mathrm{~mm}$ and $6.6 \mathrm{~mm}$, the root-mean-square errors were $2.1 \mathrm{~mm}$ and $5.2 \mathrm{~mm}$, and the reproducibility were $2.3 \mathrm{~mm}$ and $4.3 \mathrm{~mm}$, respectively [9]. Another study similarly found mean intra- and inter-fraction positional errors in the CC axis of $1.7 \mathrm{~mm}$ and $3.7 \mathrm{~mm}$, and found reproducibility of $1.5 \mathrm{~mm}$ and $3.4 \mathrm{~mm}$, respectively [10]. Of note, the SDX system is designed with individual BHL and limited breath-hold range (BHL $\pm 0.1 \mathrm{~L})$. Our results in positional error and reproducibility were consistent with those found with the $\mathrm{ABC}$ system. However, there has not been any direct study on the comparison 
Table 2 Comparison in positional errors between subgroups

\begin{tabular}{|c|c|c|c|c|}
\hline \multirow[t]{2}{*}{ Subgroup } & \multirow[t]{2}{*}{$\mathrm{n}$} & \multicolumn{3}{|c|}{ Average positional shift \pm SD (mm) } \\
\hline & & $\overline{\mathrm{AP}}$ & CC & $\mathrm{RL}$ \\
\hline Overall & 28 & $-0.48 \pm 2.54$ & $-0.85 \pm 3.72$ & $+0.41 \pm 2.35$ \\
\hline \multicolumn{5}{|l|}{ Age } \\
\hline$\leq 60 \mathrm{y} / \mathrm{o}$ & 13 & $-0.17 \pm 2.71$ & $-1.89 \pm 2.95$ & $+0.71 \pm 2.45$ \\
\hline$>60 \mathrm{y} / \mathrm{o}$ & 15 & $-0.74 \pm 2.35$ & $+0.06 \pm 4.07$ & $+0.14 \pm 2.23$ \\
\hline$p$ value & & 0.58 & 0.17 & 0.54 \\
\hline \multicolumn{5}{|l|}{ BMl } \\
\hline$\leq 22.9$ & 14 & $-0.73 \pm 2.73$ & $-0.19 \pm 2.32$ & $+0.66 \pm 2.70$ \\
\hline$>22.9$ & 14 & $-0.22 \pm 2.30$ & $-1.50 \pm 4.63$ & $+0.27 \pm 1.91$ \\
\hline$p$ value & & 0.61 & 0.38 & 0.59 \\
\hline \multicolumn{5}{|l|}{ Mean BHL } \\
\hline$\leq 1.4 \mathrm{~L}$ & 14 & $-1.34 \pm 2.00$ & $+0.90 \pm 2.64$ & $-0.03 \pm 2.30$ \\
\hline$>1.4 \mathrm{~L}$ & 14 & $+0.39 \pm 2.72$ & $-2.59 \pm 3.82$ & $+0.84 \pm 2.32$ \\
\hline$p$ value & & 0.08 & 0.01 & 0.35 \\
\hline \multicolumn{5}{|l|}{$\triangle \mathrm{BHL}$} \\
\hline$\leq 0.03 \mathrm{~L}$ & 18 & $-0.15 \pm 2.87$ & $-0.81 \pm 4.25$ & $+0.66 \pm 2.43$ \\
\hline$>0.03 \mathrm{~L}$ & 10 & $-1.06 \pm 1.65$ & $-0.90 \pm 2.50$ & $-0.06 \pm 2.14$ \\
\hline$p$ value & & 0.31 & 0.95 & 0.45 \\
\hline \multicolumn{5}{|l|}{ Liver volume } \\
\hline$\leq 1.3 \mathrm{~L}$ & 13 & $-0.43 \pm 1.59$ & $-1.38 \pm 3.80$ & $+0.65 \pm 1.92$ \\
\hline$>1.3 \mathrm{~L}$ & 15 & $-0.51 \pm 3.14$ & $-0.39 \pm 3.59$ & $+0.20 \pm 2.65$ \\
\hline$p$ value & & 0.93 & 0.50 & 0.62 \\
\hline \multicolumn{5}{|l|}{ GTV } \\
\hline$\leq 60 \mathrm{~cm}^{3}$ & 14 & $-0.60 \pm 2.06$ & $-1.49 \pm 3.30$ & $+1.09 \pm 1.72$ \\
\hline$>60 \mathrm{~cm}^{3}$ & 14 & $-0.35 \pm 2.94$ & $-0.20 \pm 4.00$ & $-0.28 \pm 2.68$ \\
\hline$p$ value & & 0.80 & 0.38 & 0.13 \\
\hline
\end{tabular}

between the limited breath-hold range with the SDX system and the breathing threshold method with the $\mathrm{ABC}$ system. In terms of peak exploratory flow (PEF), Fleisch meter by use of pneumotachograph demonstrated a more accurate PEF measurement than Wright meter and turbine spirometer [23]. Whether the pneumotachograph spirometer of the SDX system is more sensitive and accurate than the turbine spirometer of the $\mathrm{ABC}$ system remains to be validated.

However, reproducibility of breath hold is important in order to reduce positional errors. Inter-fraction variations in breath-hold position could exceed $4 \mathrm{~mm}$ with a range of $1-8 \mathrm{~mm}$, especially in the $\mathrm{CC}$ direction, even when using a pneumatic abdominal compression belt to reduce respiratory motion [24]. Therefore, our study investigated the association between breath-hold variation and positional error with the breathing-hold range limited by the SDX system. In contrast, our results showed that breath-hold variation was not significantly associated with positional errors, which means visually guided voluntary breath hold and the breath-hold range limitation of the SDX system can maintain both breath-hold consistency and patient body conformity.

The reference value of pulmonary function was related to body factors, such as height, weight, body mass index (BMI), and gender [25]. We found that patients with mean BHL > 1.4 L were significantly taller and heavier, and had larger positional errors in the $\mathrm{CC}$ direction. The physical size of patients may affect the inspiration depth and further affect the accuracy of the CC position. Notably, significance was not shown with BMI, probably because the exclusively Asian patients in this study had a smaller and narrower range of BMI than that of other populations [26]. Although our data showed that mean BHL was significantly associated with positional errors, the mean shifts were less than our PTV margin $(0.5 \mathrm{~cm})$ expanded from clinical target volume. Such positioning confidence under image guidance undoubtedly helps the radiotherapy dose coverage meet the clinical goals $[11,27]$.

Limitations of this study should be acknowledged. First, the limited number of patients was a shortcoming because we excluded several patients who did not have stents or embolized materials for image guidance. A relative smaller sample size might lead to bigger variation in statistical analysis of certain parameters. Further expansion of sample size could be overcome by continuing to enroll patients in the future.

Second, we used orthogonal images rather than CBCT in data analysis. The image acquisition by old CBCT system could not be completed in a single breath hold, so the reconstructed $\mathrm{CBCT}$ from multiple breath holds may increase the uncertainty of alignment. This shortcoming could be overcome by new CBCT system, which can nowadays be complete within one single breath hold, but no data is available for potential difference between CBCT images from single and multiple breath holds. With higher correlation between the shifts on $\mathrm{CBCT}$ with stent or embolized materials than with vertebral body on orthogonal images, $\mathrm{kV}$-orthogonal images with stent/lipiodol were used as the reference. Our ongoing work involves collecting more data from patients to expand our analysis and confirm data consistency.

\section{Conclusion}

In this study, patients treated with hepatobiliary radiotherapy using the SDX system for breath holds demonstrated effective and accurate tumor motion reduction. Actual BHL but not breath-hold precision $(\triangle B H L)$ was associated with positional errors under a predefined rigorous breath-hold protocol. Patients with larger body weight and height had significantly larger BHL and greater caudally positional error. The findings indicate that body-specific BHL plays a crucial role in positional error with breath-hold respiratory control. 


\section{Supplementary information}

Supplementary information accompanies this paper at https://doi.org/10. 1186/s12885-020-07082-y.

Additional file 1: Supplementary Figure 1. (A) Training and preparation sessions of SDX system included (a) the determination of the inspiratory capacity and (b) the selection of the volumetric value. (c) The breath-hold level was defined as $85 \%$ of the inspiratory capacity and (d) the breath-hold range was restricted within $0.1 \mathrm{~L}$. (B) During real treatment, patients were instructed by traffic light icon to distinguish (a) nonbreath-hold phase (beam off) and (b) breath-hold phase (beam on).

\section{Abbreviations}

SDX: Spirometric motion management system; CBCT: Cone-beam computed tomography; BHL: Breath-hold level; $\triangle \mathrm{BHL}$ : Breath-hold level variation; IGRT: Image-guided radiotherapy; SBRT: Stereotactic body radiotherapy; PTV: Planning target volume; DIBH: Deep inspiration breath-hold; SDX system: SpiroDynr'X system ${ }^{\oplus}$; ABC: Active breathing coordinator; PEF: Peak exploratory flow

\section{Acknowledgements}

Not applicable.

\section{Authors' contributions}

All authors have read and approved the manuscript. T.J.H.; Designed and performed experiments, and helped draft the manuscript, Y.T.; Analyzed data and helped draft the manuscript, J.K.W.; Designed and performed experiments, W.T.H.; Monitored the quality of the research, J.C.H.C.; Monitored the quality of the research, and help draft the manuscript.

\section{Funding}

Not applicable.

\section{Availability of data and materials}

The data that support the findings of this study are available from the corresponding author upon reasonable request.

\section{Ethics approval and consent to participate}

The study was approved by Institutional Review Board of National Taiwan University Hospital (IRB No.:201607043RINB, Project No.: NTUH. 106-S3556). We obtained the written consent of the patients in this study.

\section{Consent for publication}

Not applicable.

\section{Competing interests}

The authors declare no conflict of interest.

\section{Author details}

'Division of Radiation Oncology, Department of Oncology, National Taiwan University Hospital, National Taiwan University College of Medicine, No. 7 Chung-Shan South Rd, Taipei 10002, Taiwan. ${ }^{2}$ Department of Medical Imaging and Radiological Technology, Yuanpei University of Medical Technology, 306 Yuanpei Street, Hsinchu 30015, Taiwan. ${ }^{3}$ Taoyuan Psychiatric Center, Ministry of Health and Welfare, No.71, Longshou St., Taoyuan 33058, Taiwan. ${ }^{4}$ School of Medicine, College of Medicine, Fu Jen Catholic University, New Taipei, Taiwan. ${ }^{5}$ Graduate Institutes of Oncology, National Taiwan University Hospital, National Taiwan University College of Medicine, Taipei, Taiwan. ${ }^{6}$ Graduate Institutes of Clinical Medicine, National Taiwan University College of Medicine, Taipei, Taiwan.

Received: 30 January 2020 Accepted: 16 June 2020 Published online: 01 July 2020

\section{References}

1. Law AL, Ng WT, Lee MC, Chan AT, Fung KH, Li F, Lao WC, Lee AW. Treatment of primary liver cancer using highly-conformal radiotherapy with kV-image guidance and respiratory control. Radiother Oncol. 2012;102(1): 56-61.
2. Bujold A, Massey CA, Kim JJ, Brierley J, Cho C, Wong RK, Dinniwell RE, Kassam Z, Ringash J, Cummings B, Sykes J, Sherman M, Knox JJ, Dawson LA. Sequential phase I and II trials of stereotactic body radiotherapy for locally advanced hepatocellular carcinoma. J Clin Oncol. 2013, 2012.

3. Sterzing F, Brunner TB, Ernst I, Baus WW, Greve B, Herfarth K, Guckenberger M. Stereotactic body radiotherapy for liver tumors. Strahlenther Onkol. 2014; 190(10):872-81.

4. Stieler F, Fleckenstein J, Simeonova A, Wenz F, Lohr F. Intensity modulated radiosurgery of brain metastases with flattening filter-free beams. Radiother Oncol. 2013;109(3):448-51.

5. Navarria P, Ascolese AM, Mancosu P, Alongi F, Clerici E, Tozzi A, Alloisio M. Volumetric modulated arc therapy with flattening filter free (FFF) beams for stereotactic body radiation therapy (SBRT) in patients with medically inoperable early stage non-small cell lung cancer (NSCLC). Radiother Oncol. 2013;107(3):414-8.

6. Keall PJ, Mageras GS, Balter JM, Emery RS, Forster KM, Jiang SB, Ramsey CR. The management of respiratory motion in radiation oncology report of AAPM task group 76 a. Med Phys. 2006;33(10):3874-900.

7. Gong GZ, Yin Y, Xing LG, Guo YJ, Liu T, Chen J, Zhang G. RapidArc combined with the active breathing coordinator provides an effective and accurate approach for the radiotherapy of hepatocellular carcinoma. Strahlenther Onkol. 2012;188(3):262-8.

8. Remouchamps VM, Vicini FA, Sharpe MB, Kestin LL, Martinez AA, Wong JW. Significant reductions in heart and lung doses using deep inspiration breath hold with active breathing control and intensity-modulated radiation therapy for patients treated with locoregional breast irradiation. Int J Radiat Oncol Biol Phys. 2003;55(2):392-406.

9. Dawson LA, Brock KK, Kazanjian S, Fitch D, McGinn CJ, Lawrence TS, Balter J. The reproducibility of organ position using active breathing control $(A B C)$ during liver radiotherapy. Int J Radiat Oncol Biol Phys. 2001;51(5):1410-21.

10. Eccles C, Brock KK, Bissonnette JP, Hawkins M, Dawson LA. Reproducibility of liver position using active breathing coordinator for liver cancer radiotherapy. Int J Radiat Oncol Biol Phys. 2006;64(3):751-759.11.

11. Lu L, Diaconu C, Djemil T, Videtic GM, Abdel-Wahab M, Yu N, Xia P. Intraand inter-fractional liver and lung tumor motions treated with SBRT under active breathing control. J Appl Clin Med Physics. 2018;19(1):39-45.

12. Linthout N, Bral S, Van de Vondel I, Verellen D, Tournel K, Gevaert T, Storme $\mathrm{G}$. Treatment delivery time optimization of respiratory gated radiation therapy by application of audio-visual feedback. Radiother Oncol. 2009;91(3): $330-5$.

13. Kimura T, Murakami Y, Kenjo M, Kaneyasu Y, Wadasaki K, Ito K, Ohkawa M. Interbreath-hold reproducibility of lung tumour position and reduction of the internal target volume using a voluntary breath-hold method with spirometer during stereotactic radiotherapy for lung tumours. Br J Radiol. 2007:80(953):355-61.

14. Case RB, Sonke JJ, Moseley DJ, Kim J, Brock KK, Dawson LA. Inter-and intrafraction variability in liver position in non-breath-hold stereotactic body radiotherapy. Int J Radiat Oncol Biol Phys. 2009;75(1):302-8.

15. Brock KK. Imaging and image-guided radiation therapy in liver cancer. Semin Radiat Oncol. 2011;21(4):247-55 WB Saunders.

16. Hawkins MA, Brock KK, Eccles C, Moseley D, Jaffray D, Dawson LA. Assessment of residual error in liver position using $\mathrm{kV}$ cone-beam computed tomography for liver cancer high-precision radiation therapy. Int J Radiat Oncol Biol Phys. 2006;66(2):610-9.

17. Wong JW, Sharpe MB, Jaffray DA, Kini VR, Robertson JM, Stromberg JS, Martinez AA. The use of active breathing control $(A B C)$ to reduce margin for breathing motion. Int J Radiat Oncol Biol Phys. 1999;44(4):911-9.

18. Zhao JD, Xu ZY, Zhu J, Qiu JJ, Hu WG, Cheng LF, Zhang XJ, Jiang GL. Application of active breathing control in 3-dimensional conformal radiation therapy for hepatocellular carcinoma: the feasibility and benefit. Radiother Oncol. 2008;87(3):439-44.

19. Dawson LA, Eccles C, Bissonnette JP, Brock KK. Accuracy of daily image guidance for hypofractionated liver radiotherapy with active breathing control. Int J Radiat Oncol Biol Phys. 2005;62(4):1247-52.

20. Pommier P, Morelle M, Perrier L, Laplanche A, Dudouet $P$, Mahé MA, Chapet O. Prospective economic evaluation of image-guided radiation therapy for prostate cancer in the framework of the national programme for innovative and costly therapies assessment. Cancer Radiothérapie. 2012;16(5-6):444-51.

21. Habermehl D, Naumann P, Bendl R, Oelfke U, Nill S, Debus J, Combs SE. Evaluation of inter- and intrafractional motion of liver tumors using interstitial markers and implantable electromagnetic radiotransmitters in the 
context of image-guided radiotherapy (IGRT) - the ESMERALDA trial. Radiat Oncol (London, England). 2015;10:143.

22. Zhong R, Wang J, Jiang X, He Y, Zhang H, Chen N, Bai S, Xu F. Hypofraction radiotherapy of liver tumor using cone beam computed tomography guidance combined with active breath control by long breath-holding. Radiother Oncol. 2012;104(3):379-85.

23. Bongers T, O'driscoll BR. Effects of equipment and technique on peak flow measurements. BMC Pulmon Med. 2006;6(1):14.

24. Lovelock DM, Zatcky J, Goodman K, Yamada Y. The effectiveness of a pneumatic compression belt in reducing respiratory motion of abdominal tumors in patients undergoing stereotactic body radiotherapy. Technol Cancer Res Treatment. 2014;13(3):259-67.

25. Barroso AT, Martín EM, Romero LMR, Ruiz FO. Factors affecting lung function: a review of the literature. Arch Bronconeumol (English Edition). 2018:54(6):327-32.

26. Hashimoto S, Katsurada M, Muramatsu R, Asai K, Tanaka K, Hayashi K, Mizoe JE. Effect of a device-free compressed Shell fixation method on hepatic respiratory movement: analysis for respiratory amplitude of the liver and internal motions of a Fiducial marker. Practical Radiat Oncol. 2019;9(2):e149-55.

27. Crane $\mathrm{CH}$, Koay EJ. Solutions that enable ablative radiotherapy for large liver tumors: fractionated dose painting, simultaneous integrated protection, motion management, and computed tomography image guidance. Cancer. 2016;122(13):1974-86.

\section{Publisher's Note}

Springer Nature remains neutral with regard to jurisdictional claims in published maps and institutional affiliations.

Ready to submit your research? Choose BMC and benefit from:

- fast, convenient online submission

- thorough peer review by experienced researchers in your field

- rapid publication on acceptance

- support for research data, including large and complex data types

- gold Open Access which fosters wider collaboration and increased citations

- maximum visibility for your research: over $100 \mathrm{M}$ website views per year

At BMC, research is always in progress.

Learn more biomedcentral.com/submissions 